\title{
Original
}

\section{Thyroxine treatment may be useful for subclinical hypothyroidism in patients with female infertility}

\author{
Waka Yoshioka, Nobuyuki Amino, Akane Ide, Shino Kang, Takumi Kudo, Eijun Nishihara, Mitsuru Ito, \\ Hirotoshi Nakamura and Akira Miyauchi
}

Kuma Hospital, Center for Excellence in Thyroid Care, Kobe 650-0011, Japan

\begin{abstract}
Infertile women sometimes associated with subclinical hypothyroidism (SCH). The guidelines of the American Endocrine Society, and American Association of Clinical Endocrinologists and American Thyroid Association recommend treatment with thyroxine (T4) for patients with $\mathrm{SCH}$ who want to have children. We examined 69 female infertile patients with SCH and the effects of levothyroxine (1-T4) therapy on pregnancy rates and pregnancy outcomes were observed. Fifty-eight (84.1\%) patients successfully conceived during the T4 treatment period (Group A), although 17 patients (29.3\%) had miscarriage afterward. The remaining 11 patients continued to be infertile (Group B). The median TSH value in Group A before the T4 treatment was $5.46 \mu \mathrm{IU} / \mathrm{mL}$ (range 3.1-13.3) and this significantly decreased to $1.25 \mu \mathrm{IU} / \mathrm{mL}$ (range 0.02 $3.75)$ during the treatment $(p<0.001)$. The estimated duration of infertility before the T4 treatment was $2.8 \pm 1.7$ years and the duration until pregnancy after the treatment was significantly shorter at $0.9 \pm 0.9$ years $(p<0.001)$. Shortening of the infertile period after the T4 therapy was observed not only in patients who were treated with assisted reproductive technology (ART) but also in patients who conceived spontaneously in Group A. Administered T4 dose was 54.3 $\pm 14.2 \mu \mathrm{g}$ before pregnancy and $68.5 \pm 22.8 \mu \mathrm{g}$ during pregnancy $(p<0.001)$. Anti-thyroid autoantibodies were identified in $42.0 \%$ of all patients and no significant difference was observed in positivity between Group A and Group B. High successful pregnancy rate and shorter duration of infertility until pregnancy after T4 treatment strongly suggest that T4 enhanced fertility in infertile patients with SCH.
\end{abstract}

Key words: Subclinical hypothyroidism, Infertility, Thyroxine therapy, Anti-thyroid antibodies, Pregnancy

UNDERSTANDING of the effect of thyroid disease on pregnancy process has been advanced significantly $[1,2]$. Subclinical hypothyroidism $(\mathrm{SCH})$ is frequently associated with various disorders including cardiovascular disease, heart dysfunction, disturbed lipid metabolism, and obstetric complications, and treatment with T4 has been shown to improve these conditions, although this treatment remains controversial [3]. The prevalence of $\mathrm{SCH}$ in female infertility is very variable ranging from $0.9 \%$ to $43 \%$ [4-6], however, an Endocrine Society Clinical Practice Guideline on the Management of Thyroid Dysfunction during Pregnancy and Postpartum recommends screening of serum TSH levels in infertile women [7]. The Committee considers a low-dose T4 treatment to be appropriate for reduc-

Submitted Jun. 27, 2014; Accepted Sep. 19, 2014 as EJ14-0300 Released online in J-STAGE as advance publication Oct.10, 2014 Correspondence to: Nobuyuki Amino, M.D., Kuma Hospital, 8-235 Shimoyamate-dori, Chuo-ku, Kobe 650-0011, Japan.

E-mail:namino@kuma-h.or.jp

(c) The Japan Endocrine Society ing prenatal repeated serum TSH levels above $2.5 \mu \mathrm{IU} /$ $\mathrm{mL}$ to below $2.5 \mu \mathrm{IU} / \mathrm{mL}$. Clinical Practice Guidelines for Hypothyroidism by the American Association of Clinical Endocrinologists and American Thyroid Association also recommend that treatment with $\mathrm{T} 4$ should be considered in women of childbearing age with serum TSH levels between $2.5 \mu \mathrm{IU} / \mathrm{mL}$ and the upper limit of normal for a given laboratory's reference range if they are planning a pregnancy including assisted reproduction in the immediate future [8].

However, a few studies are available on the effects of T4 treatment on infertility in women with $\mathrm{SCH}$ but results are variable [9-12]. Scoccia et al. reported that, despite T4 treatment, women with hypothyroidism had significantly less implantation, clinical pregnancy and live birth rates than euthyroid women in their in vitro fertilization (IVF) study [12]. More recently Chai et al. reported that live birth and miscarriage rates were not impaired among women who were thyroid autoimmunity positive and/or had preconception subclinical 
hypothyroidism with TSH $>2.5 \mu \mathrm{IU} / \mathrm{mL}$ [13]. In this study, therefore, we examined the effects of $\mathrm{T} 4$ treatment on infertility in women with $\mathrm{SCH}$.

\section{Materials and Methods}

\section{Patients}

We prospectively examined 69 infertile patients with SCH between January 2007 and December 2012. These patients were referred to our Kuma Hospital from the 16 infertility clinics because of high TSH found by screening tests. Infertility was diagnosed in patients who were fundamentally unable to conceive a baby for at least one year. Patients with male cause of infertility in their partners have been excluded. When high TSH more than $3.0 \mu \mathrm{IU} / \mathrm{mL}$ was reconfirmed in Kuma Hospital, treatment with 25 to $50 \mu \mathrm{g}$ per day of T4 was started. When starting T4 treatment, 9 patients were under treatment with artificial insemination by husband $(\mathrm{AIH})$ or ART and the rest 60 patients were not treated with these techniques yet. T4 dose was adjusted to keep TSH levels less than $3.0 \mu \mathrm{IU} / \mathrm{mL}$ before pregnancy and less than $2.5 \mu \mathrm{IU} / \mathrm{mL}$ during pregnancy. Finally patients were divided into two groups: successfully conceived, Group A and could not conceive, Group B. Patients were informed of the therapy and gave their consent to the study. The protocol was approved by the Ethical Committee of Kuma Hospital.

Normal range of TSH in Japanese women of childbearing age and the definition of $\mathrm{SCH}$

Since TSH values are known to be influenced by age, ethnic differences, and measuring assay kits, we attempted to establish the normal range of TSH in Japanese women of childbearing age using 131 normal women aged between 15 and 45 years old (mean 34). Subjects taking excess iodine and with positive $\mathrm{TgAb}$ and/or TPOAb or an abnormal thyroid, as confirmed by ultrasonography were excluded. The $95 \%$ confidence interval was found to be 0.39 to $3.04 \mu \mathrm{IU} / \mathrm{mL}$. Therefore, the diagnosis of $\mathrm{SCH}$ was made by normal Free T4 (FT4) and TSH levels of more than $3.0 \mu \mathrm{IU} / \mathrm{mL}$.

\section{Thyroid function and autoantibodies}

TSH, FT4, and Free T3 (FT3) concentrations were measured using chemiluminescent immunoassays (Architect TSH, Architect FT4, and Architect FT3, respectively; Abbott Japan Co., Tokyo, Japan). Normal ranges were $0.4-3.0 \mu \mathrm{IU} / \mathrm{mL}$ for TSH, $0.7-1.4 \mathrm{ng} / \mathrm{dL}$ for
FT4, and 1.8-3.5 pg/mL for FT3. Inter-assay CVs of measurements for normal TSH levels were 2.0 3.0\%. Serum levels of the thyroglobulin antibody (TgAb) and anti-thyroid peroxidase antibody (TPOAb) were measured using an electrochemiluminescence immunoassay (ECLusys 2010; Roche Diagnostics Japan Co., Tokyo, Japan; normal range: $<39.9 \mathrm{IU} / \mathrm{mL}$ for $\mathrm{TgAb}$, and $<27.9 \mathrm{IU} / \mathrm{mL}$ for TPOAb).

\section{Statistical analysis}

Comparisons of TSH values and the estimated durations of infertility before and after the T4 treatment were performed by the paired T test for paired samples. A comparison of T4 administered before and during pregnancy was also calculated by the paired $\mathrm{T}$ test. Differences in age, prevalence of antibodies, and infertility treatment were analyzed between Group A and Group B by the Mann-Whitney test, Fisher exact test or chi square test. Differences were considered to be significant at $p<0.05$.

\section{Results}

Fifty-eight of $69(84.1 \%)$ infertile women with SCH successfully conceived after the T4 treatment (Group A). The remaining 11 patients continued to be infertile (Group B) for observation period of $3.3 \pm 2.2$ years $(0.6 \sim 6$ years) (Table 1$)$. No significant difference was observed in the age and prevalence or activities of TgAb and/or TPOAb between the two groups. Regarding the infertility treatment method, 25 patients were observed spontaneously or with timed intercourse, 9 with AIH, 33 with in vitro fertilization-embryo transfer (IVF-ET), and 2 with intracytoplasmic sperm injection (ICSI) (Table 1). The treatment proportions of none (including timed intercourse), AIH or ART (IVF-ET and ICSI) were similar between two groups (Table 1). The median TSH and mean FT4 values before the $\mathrm{T} 4$ treatment (data at first visit) were also similar between two groups. The median TSH values in Group A before the T4 treatment was 5.46 (range 3.1-13.3) $\mu \mathrm{IU} / \mathrm{mL}$ and significantly decreased to 1.25 (range $0.02-3.75) \mu \mathrm{IU} / \mathrm{mL}(p<0.001)$ after the treatment for 2 4 months (Table 1). In Group B similar changes in TSH were observed, before 5.10 (range 3.117.4) $\mu \mathrm{IU} / \mathrm{mL}$ and after 1.90 (range 0.07-4.43) $\mu \mathrm{IU} /$ $\mathrm{mL}$. The FT4 values in Group A before the T4 treatment was $0.98 \pm 0.13 \mathrm{ng} / \mathrm{dl}$ and significantly increased to $1.23 \pm 0.22 \mathrm{ng} / \mathrm{dL}(p<0.001)$ after the treatment. The FT3 values before the T4 treatment was $2.75 \pm 0.32 \mathrm{pg} /$ 
Table 1 Clinical and laboratory data in infertile patients with subclinical hypothyroidism: Comparison between successful and unsuccessful pregnancy after the thyroxine treatment

\begin{tabular}{|c|c|c|c|c|c|c|c|c|c|c|c|c|c|c|}
\hline \multirow{2}{*}{ Pregnancy } & \multirow{2}{*}{$\mathrm{n}$} & \multirow{2}{*}{$\begin{array}{l}\text { Age } \\
\text { (years) }\end{array}$} & \multicolumn{2}{|c|}{$\begin{array}{c}\text { Median TSH } \\
\text { value }(\mu \mathrm{IU} / \mathrm{mL}) \\
\end{array}$} & \multicolumn{2}{|c|}{$\begin{array}{c}\text { FT4 } \\
\text { (ng/dL) }\end{array}$} & \multicolumn{2}{|c|}{$\begin{array}{l}\text { No.of positive } \\
\text { antibodies }\end{array}$} & \multicolumn{2}{|c|}{$\begin{array}{c}\text { Activities of } \\
\text { autoantibodies }(\mathrm{U} / \mathrm{mL})\end{array}$} & \multicolumn{4}{|c|}{$\begin{array}{l}\text { Infertility treatment } \\
\text { (Patient no.) }\end{array}$} \\
\hline & & & $\begin{array}{l}\text { Before } \\
\text { T4 }\end{array}$ & $\begin{array}{l}\text { After } \\
\text { T4 }\end{array}$ & $\begin{array}{l}\text { Before } \\
\text { T4 }\end{array}$ & $\begin{array}{c}\text { After } \\
\text { T4 }\end{array}$ & $\mathrm{TgAb}$ & ГРОАЬ & $\mathrm{TgAb}$ & TPOAb & None & $\mathrm{AIH}$ & IVF-ET & ICSI \\
\hline $\begin{array}{l}\text { Successful } \\
\text { (Group A) }\end{array}$ & 58 & $34.8 \pm 3.9$ & 5.46 & $1.25^{*}$ & $0.98 \pm 0.13$ & $1.23 \pm 0.22^{*}$ & 23 & 14 & $233 \pm 547$ & $86 \pm 149$ & 21 & 6 & 29 & 2 \\
\hline $\begin{array}{l}\text { Unsuccessful } \\
\text { (Group B) }\end{array}$ & 11 & $35.1 \pm 3.9$ & 5.10 & $1.90^{*}$ & $1.00 \pm 0.14$ & $1.20 \pm 0.20^{*}$ & 5 & 3 & $64 \pm 34$ & $113 \pm 178$ & 4 & 3 & 4 & 0 \\
\hline
\end{tabular}

${ }^{*}$ Significantly different from value of before T4 treatment at $p<0.001$

$\mathrm{AIH}$, artificial insemination by husband; IVF-ET, in vitro fertilization-embryo transfer; ICSI, intracytoplasmic sperm injection

Table 2 Clinical and laboratory data in patients with successful pregnancy

\begin{tabular}{lcccccc}
\hline \multicolumn{3}{c}{ Duration of infertility (years) } & & \multicolumn{3}{c}{ Used dose of T4 $(\mu \mathrm{g} /$ day $)$} \\
\cline { 1 - 3 } \cline { 5 - 7 } Infertility treatment & None & AIH+ART & & Infertility treatment & None & AIH+ART \\
\cline { 1 - 5 } Before T4 treatment & $2.1 \pm 1.4$ & $3.1 \pm 1.7$ & & Before pregnancy & $55.8 \pm 12.9$ & $53.5 \pm 15.0$ \\
After T4 treatment & $0.8 \pm 1.1^{*}$ & $0.9 \pm 0.8^{*}$ & & During pregnancy & $70.8 \pm 19.2^{* *}$ & $67.2 \pm 23.3^{* *}$ \\
\hline
\end{tabular}

Data are mean $\pm \mathrm{SD} .{ }^{*}$ Significantly different from duration before T4 treatment at $p<0.001$

** Significantly different from the dose before pregnancy at $p<0.001$

$\mathrm{AIH}$, artificial insemination by husband; ART, artificial reproductive technology
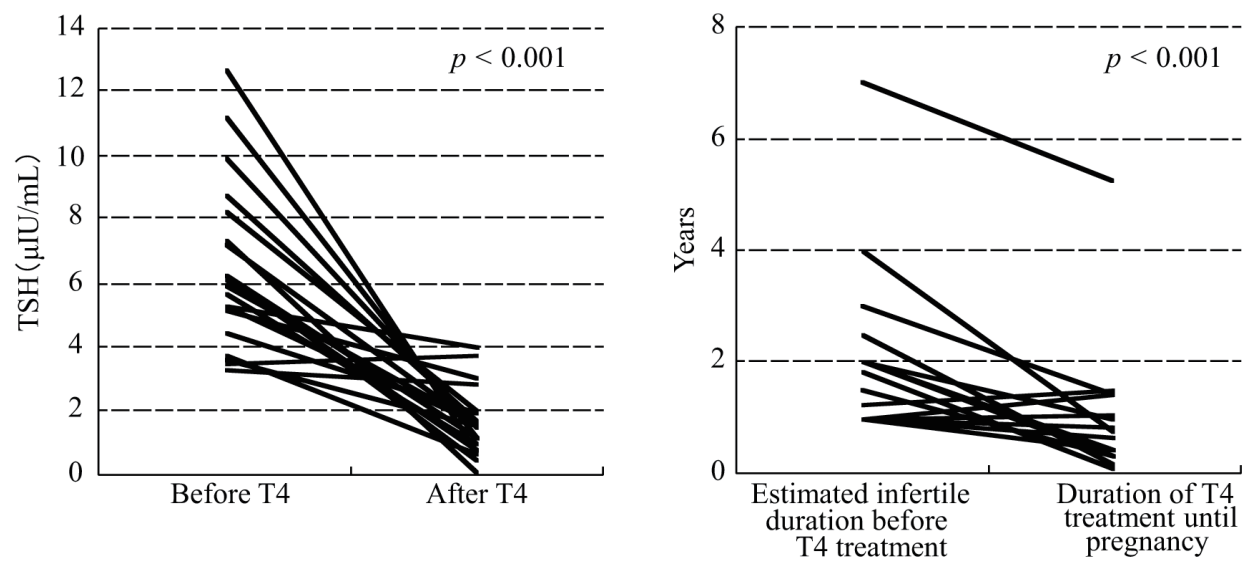

Fig. 1 Comparison of serum TSH levels and infertile duration before and after the T4 treatment in patients who conceived spontaneously without AIH or ART treatment.

$\mathrm{mL}$ and did not change after the treatment $(2.78 \pm 0.46$ $\mathrm{pg} / \mathrm{mL}$ ). In Group B similar changes in FT4 were observed (Table 1).

The estimated duration of infertility in Group A was compared between before and after the T4 treatment until pregnancy in both groups of no infertility treatment and AIH+ART treatment (Table 2). The infertile period was similarly shorter after the $\mathrm{T} 4$ treatment in both groups $(p<0.001)$. In all 58 patients, $2.8 \pm 1.7$ years reduced to $0.9 \pm 0.9$ years $(p<0.001)$ after T4 treatment. Used dose of T4 was higher during pregnancy than that of before pregnancy in both groups $(p<0.001)$
(Table 2). A moderate dose of T4 was needed before pregnancy $(54.3 \pm 14.2 \mu \mathrm{g}$ per day) and a larger dose (68.5 $\pm 21.8 \mu \mathrm{g}$ per day) were necessary to keep TSH less than $2.5 \mu \mathrm{IU} / \mathrm{mL}$ during pregnancy in Group A. Twelve patients $(20.7 \%)$ in group A conceived within 3 months and $14(24.1 \%)$ conceived within 6 months. Finally, 44 patients $(75.8 \%)$ had conceived within one year after the T4 treatment.

In order to remove the possible effects of AIH or ART technologies, we analyzed patients who conceived spontaneously before and after T4 treatment (including timed intercourse). As shown in Fig. 1, high TSH levels 
Table 3 Clinical and laboratory data in successful pregnancy: Comparison between live birth or pregnancy more than 24 weeks and miscarriage

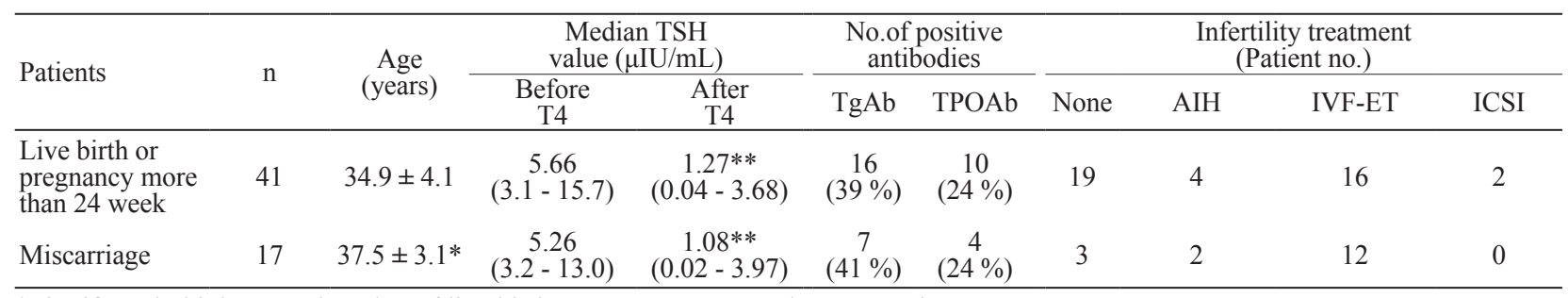

*Significantly higher age than that of live birth or pregnancy more than 24 weeks at $p<0.05$

** Significantly different from value of before T4 treatment at $p<0.001$

$\mathrm{AIH}$, artificial insemination by husband; IVF-ET, in vitro fertilization-embryo transfer; ICSI, intracytoplasmic sperm injection

(median 6.14, range 3.3-12.7 $\mu \mathrm{IU} / \mathrm{mL}$ ) decreased significantly (median 1.57, range $0.01-4.0 \mu \mathrm{IU} / \mathrm{mL})(p<0.001)$ by the $\mathrm{T} 4$ treatment. The estimated infertile period before the T4 treatment ( $2.1 \pm 1.4$ years) was also significantly shortened $(0.87 \pm 1.1$ years $)(p<0.001)$ (Table 2$)$. We examined non-thyroidal infertility factors, such as endometriosis, other uterine problems, ovarian and tubal factors, anti-phospholipid antibodies and anti-nuclear antibodies. These factors were found in $32.8 \%$ and $45.6 \%$ in Group A and Group B, respectively, but difference was not significant between the two.

A high pregnancy rate was observed after T4 treatment in the present study; however, 17 cases (29.3\%) had a miscarriage. We analyzed various factors between the subgroup of live birth or continued pregnancy more than 24 gestational weeks (non-miscarriage subgroup) and miscarriage subgroup (Table 3). Mean age at pregnancy in miscarriage subgroup was $37.5 \pm 3.1$ and significantly higher than that of non-miscarriage subgroup $(34.9 \pm 4.1, p<0.05)$. AIH or ART therapy were conducted in $82.3 \%$ of patients in miscarriage subgroup and was $53.6 \%$ in non-miscarriage subgroup, and difference between the two was significant $(p<0.05)$. Anti-thyroid autoantibodies were similarly found in $39 \%$ and $41 \%$ in non-miscarriage and miscarriage subgroups, respectively. Non-thyroidal miscarriage factors, such as endometriosis, other uterine problems, anti-phospholipid antibodies and anti-nuclear antibodies, were found in $24.4 \%$ and $35.3 \%$ in non-miscarriage and miscarriage subgroups, respectively, but difference between the two was not significant.

\section{Discussion}

We found $84.1 \%$ of infertile women with $\mathrm{SCH}$ successfully conceived after the T4 treatment. Moreover,
$75.8 \%$ of them had conceived within one year after initiation of treatment. SCH has various causes and $60 \sim 80 \%$ of cases are associated with autoimmune thyroiditis [3]. On the other hand, anti-thyroid antibodies were found in $1.9 \sim 30.5 \%$ of infertile patients [4]. It is well described that positive anti-thyroid antibodies are associated with high frequency of miscarriage [2, 15-17] but thyroid autoimmunity per se does not alter the implantation of embryo[17, 18]. In this study, anti-thyroid antibodies were found in $42.0 \%$ of patients but no significant differences were observed between Group A and Group B, suggesting that presence of antithyroid antibodies may not be a key factor of fertility.

In 1999, Lincoln et al. [19] reported that thyroxine treatments for hypothyroidism in infertile women with ovulatory dysfunction resulted in successful pregnancies in $64 \%$ of patients. None of these women had the overt clinical signs or symptoms of hypothyroidism, which suggested that the T4 treatment for probable $\mathrm{SCH}$ enhanced fertility. Abalovich et al. [9] examined $34 \mathrm{SCH}$ women with infertility. They reported a pregnancy rate of $44.1 \%$ with a $\mathrm{T} 4$ treatment; however, the precise dose of T4, duration of infertility, and other information including the ART treatment were not described. Verma et al. [10] more recently reported that $76.6 \%$ of infertile patients with hypothyroidism, both the clinical and subclinical forms, conceived within one year of receiving a T4 treatment. However, the effectiveness of $\mathrm{T} 4$ only in patients with $\mathrm{SCH}$ remains unknown and no information is available on the ART treatment. The clinical pregnancy rate was shown to be significantly higher in T4-treated infertile patients with $\mathrm{SCH}$ undergoing in vitro fertilization than in those not receiving the T4 treatment $[11,20]$, although effect of T4 therapy was doubtful in other reports $[2,12$, 13]. In our study, $84.1 \%$ of infertile patients with $\mathrm{SCH}$ 
conceived after the T4 treatment, strongly suggesting that $\mathrm{T} 4$ treatments for infertile women with $\mathrm{SCH}$ may induce a favorable effect on fertility.

Recent progress in ART technique may increase the fertility rate. However, high pregnancy rate $(84.0 \%$, 21/25) obtained in patients without AIH or ART therapy (Table 1), strongly suggests that the T4 treatment itself was useful for enhancing fertility. The shorter infertility period observed after the T4 treatment without ART therapy in Group A further supports the effectiveness of the T4 treatment. We compared non-thyroidal infertile factors between Group A and Group B, but could not find significant difference between the two.

A high pregnancy rate induced by the $\mathrm{T} 4$ treatment is a desirable result for infertile women with $\mathrm{SCH}$ but problem is a high miscarriage rate. It is well established that anti-thyroid autoantibodies are significantly associated with higher miscarriage rate [2, 15-17]. However, positivity was similar between non-miscarriage and miscarriage subgroups. Verga et al. [21] reported the importance of L-T4 substitutive therapy in pregnant women with $\mathrm{SCH}$, especially in the first trimester of pregnancy. However we could not find differences in TSH values before miscarriage between non-miscarriage and miscarriage subgroups. Mean age at pregnancy was high and frequency of AIH or ART therapy was also high in miscarriage subgroup, suggesting that age and infertility therapy were significantly related to the miscarriage. It is important to elucidate more precisely the mechanisms of these abortions.

The mechanism for the T4-induced enhancement in fertility has not yet been elucidated in detail. Possibly $\mathrm{SCH}$ influence the hypothalamus-pituitary-gonadal axis and may cause menstrual abnormalities, anovulation, hyperprolactinaemia and so on $[4,22]$ and T4 therapy may improve these conditions [14, 23]. Cramer et al. reported that TSH may predict for fertilization in IVF and reflect the importance of thyroid hormones in oocyte physiology [24]. Kim et al. reported that T4 treatment may stimulate directly oocyte and improve embryo quality in their successful study of in vitro fertilization / intracytoplasmic sperm injection in infertile $\mathrm{SCH}$ women [20].

Finally, randomized controlled trials involving infertile patients with $\mathrm{SCH}$ need to be conducted in order to confirm the effectiveness of the T4 treatment. This may ultimately provide reliable evidence to make clinical decisions in the treatment of SCH patients with $\mathrm{T} 4$.

In conclusion, the $\mathrm{T} 4$ treatment for infertile patients with SCH may be useful for enhancing fertility.

\section{Financial Disclosure}

None of the authors have any potential conflicts of interest associated with this research.

\section{References}

1. Lazarus JH, Kokandi A (2000) Thyroid disease in relation to pregnancy: a decade of change. Clin Endocrinol (Oxf) 53: 265-278.

2. Poppe K, Velkeniers B, Glinoer D (2007) Thyroid disease and female reproduction. Clin Endocrinol (Oxf) 66: 309-321

3. Cooper DS, Biondi B (2012) Subclinical thyroid disease. Lancet 379: 1142-1154.

4. Krassas GE, Poppe K, Glinoer D (2010) Thyroid function and human reproductive health. Endocr Rev 31: 702-755.

5. Gerhard I, Becker T, Eggert-Kruse W, Klinga K, Runnebaum B (1991) Thyroid and ovarian function in infertile women. Hum Reprod 6: 338-345.

6. Poppe K, Glinoer D, Van Steirteghem A, Tournaye H, Devroey P, et al. (2002) Thyroid dysfunction and autoimmunity in infertile women. Thyroid 12: 997-1001.

7. DeGroot L, Abalovich M, Alexander EK, Amino N, Barbour L, et al. (2012) Management of thyroid dysfunction during pregnancy and postpartum: an Endocrine Society clinical practice guideline. J Clin Endocrinol Metab 97: 2543-2565.

8. Garber JR, Cobin RH, Gharib H, Hennessey JV, Klein I, et al. (2012) Clinical practice guidelines for hypothyroidism in adults: cosponsored by the American Association of Clinical Endocrinologists and the American Thyroid Association. Thyroid 22: 1200-1235.

9. Abalovich M, Mitelberg L, Allami C, Gutierrez S, Alcaraz G, et al. (2007) Subclinical hypothyroidism and thyroid autoimmunity in women with infertility. Gynecol Endocrinol 23: 279-283.

10. Verma I, Sood R, Juneja S, Kaur S (2012) Prevalence of hypothyroidism in infertile women and evaluation of response of treatment for hypothyroidism on infertility. Int J Appl Basic Med Res 2: 17-19.

11. Abdel Rahman AH, Aly Abbassy H, Abbassy AA (2010) Improved in vitro fertilization outcomes after treatment of subclinical hypothyroidism in infertile 
women. Endocr Pract 16: 792-797.

12. Scoccia B, Demir H, Kang Y, Fierro MA, Winston NJ (2012) In vitro fertilization pregnancy rates in levothyroxine-treated women with hypothyroidism compared to women without thyroid dysfunction disorders. Thyroid 22: 631-636.

13. Chai J, Yeung WY, Lee CY, Li HW, Ho PC, et al. (2014) Live birth rates following in vitro fertilization in women with thyroid autoimmunity and/or subclinical hypothyroidism. Clin Endocrinol (Oxf) 80: 122-127.

14. Poppe K, Velkeniers B, Glinoer D (2008) The role of thyroid autoimmunity in fertility and pregnancy. Nat Clin Pract Endocrinol Metab 4: 394-405.

15. Iijima T, Tada H, Hidaka Y, Mitsuda N, Murata Y, et al. (1997) Effects of autoantibodies on the course of pregnancy and fetal growth. Obstet Gynecol 90: 364-369.

16. Chen L, Hu R (2011) Thyroid autoimmunity and miscarriage: a meta-analysis. Clin Endocrinol (Oxf) 74: 513-519.

17. Artini PG, Uccelli A, Papini F, Simi G, Di Berardino OM, et al. (2013) Infertility and pregnancy loss in euthyroid women with thyroid autoimmunity. Gynecol Endocrinol 29: 36-41.

18. Poppe K, Glinoer D, Tournaye H, Devroey P, van Steirteghem A, et al. (2003) Assisted reproduction and thyroid autoimmunity: an unfortunate combination? $J$ Clin Endocrinol Metab 88: 4149-4152.

19. Lincoln SR, Ke RW, Kutteh WH (1999) Screening for hypothyroidism in infertile women. $J$ Reprod Med 44: 455-457.

20. Kim CH, Ahn JW, Kang SP, Kim SH, Chae HD, et al. (2011) Effect of levothyroxine treatment on in vitro fertilization and pregnancy outcome in infertile women with subclinical hypothyroidism undergoing in vitro fertilization / intracytoplasmic sperm injection. Fertil Steril 95: 1650-1654.

21. Verga U, Bergamaschi S, Cortelazzi D, Ronzoni S, Marconi AM, et al. (2009) Adjustment of L-T4 substitutive therapy in pregnant women with subclinical, overt or post-ablative hypothyroidism. Clin Endocrinol (Oxf) 70: 798-802.

22. Sharma N, Baliarsingh S, Kaushik GG (2012) Biochemical association of hyperprolactinemia with hypothyroidism in infertile women. Clin Lab 58: 805810.

23. Velkeniers B, Van Meerhaeghe A, Poppe K, Unuane D, Tournaye H, et al. (2013) Levothyroxine treatment and pregnancy outcome in women with subclinical hypothyroidism undergoing assisted reproduction technologies: systematic review and meta-analysis of RCTs. Hum Reprod Update 19: 251-258.

24. Cramer DW, Sluss PM, Powers RD, McShane P, Ginsburgs ES, et al. (2003) Serum prolactin and TSH in an in vitro fertilization population: is there a link between fertilization and thyroid function? $J$ Assist Reprod Genet 20: 210-215. 